\title{
Dual Inhibition of Nitric Oxide and Prostaglandin Production Contributes to the Antiinflammatory Properties of Nitric Oxide Synthase Inhibitors
}

\author{
Daniela Salvemini, Pamela T. Manning, Ben S. Zweifel, Karen Seibert, Jane Connor, Mark G. Currie, Philip Needleman, \\ and Jaime L. Masferrer \\ Inflammatory Diseases Research, G. D. Searle Co., St. Louis, Missouri 63167
}

\begin{abstract}
We have recently put forward the hypothesis that the dual inhibition of proinflammatory nitric oxide (NO) and prostaglandins (PG) may contribute to the antiinflammatory properties of nitric oxide synthase (NOS) inhibitors. This hypothesis was tested in the present study. A rapid inflammatory response characterized by edema, high levels of nitrites ( $\mathrm{NO}_{2}^{-}$, a breakdown product of NO), PG, and cellular infiltration into a fluid exudate was induced by the administration of carrageenan into the subcutaneous rat air pouch. The time course of the induction of inducible nitric oxide synthase (iNOS) protein in the pouch tissue was found to coincide with the production of $\mathrm{NO}_{2}^{-}$. Dexamethasone inhibited both iNOS protein expression and $\mathrm{NO}_{2}^{-}$synthesis in the fluid exudate $\left(\mathrm{IC}_{50}=0.16 \mathrm{mg} / \mathrm{kg}\right)$. Oral administration of $N$-iminoethyl-L-lysine (L-NIL) or $N^{\mathrm{G}}$-nitro-L-arginine methyl ester $\left(\mathrm{NO}_{2} \mathrm{Arg}\right)$ not only blocked nitrite accumulation in the pouch fluid in a dose-dependent fashion but also attenuated the elevated release of PG. Finally, carrageenan administration produced a time-dependent increase in cellular infiltration into the pouch exudate that was inhibited by dexamethasone and NOS inhibitors. At early times, i.e., 6 $h$, the cellular infiltrate is composed primarily of neutrophils (98\%). Pretreatment with colchicine reduced both neutrophil infiltration and leukotriene $\mathbf{B}_{4}$ accumulation in the air pouch by $98 \%$ but did not affect either $\mathrm{NO}_{2}^{-}$or PG levels.

In conclusion, the major findings of this paper are that (a) selective inhibitors of iNOS are clearly antiinflammatory agents by inhibiting not only NO but also PG and cellular infiltration and $(b)$ that neutrophils are not responsible for high levels of NO and PG produced. (J. Clin. Invest. 1995. 96:301-308.) Key words: nitric oxide $\bullet N$-iminoethyl-L-lysine $\cdot$ prostaglandin $\cdot$ dexamethasone $\cdot$ carrageenan

\section{Introduction}

Nitric oxide (NO $)^{1}$ is formed from the terminal guanidino nitrogen atom of L-arginine by nitric oxide synthase (NOS). Two

Address correspondence to Dr. Daniela Salvemini, Department of Molecular Pharmacology, Searle Inflammatory Diseases Research, G. D. Searle, 800 N. Lindbergh, St. Louis, MO 63167. Phone: 314-694-5705; FAX: 314-694-8949.

Received for publication 27 October 1994 and accepted in revised form 6 March 1995.

1. Abbreviations used in this paper: cNOS, constitutive NOS; COX, cyclooxygenase; iNOS, inducible NOS; L-NIL, $N$-iminoethyl-L-lysine; $\mathrm{NO}$, nitric oxide; $\mathrm{NO}_{2} \mathrm{Arg}, N^{\mathrm{G}}$-nitro-L-arginine-methyl ester; NOS, nitric oxide synthase.

J. Clin. Invest.

(C) The American Society for Clinical Investigation, Inc.

0021-9738/95/07/0301/08 \$2.00

Volume 96, July 1995, 301-308 major forms of NOS have been identified (for review see reference 1). Under normal physiological conditions, the constitutive, calcium-dependent NOS isoform (cNOS) is present in numerous cells including endothelium and neurons (for review see reference 1 ). In an inflammatory setting or in the presence of endotoxin and cytokines, the inducible, calcium-independent NOS isoform (iNOS) is expressed in numerous cell types including endothelial cells, smooth muscle cells, and macrophages (for reviews see references 1 and 2). Production of low levels of NO from cNOS functions to regulate a number of homeostatic processes, whereas generation of larger quantities of NO from iNOS accounts for its proinflammatory and cytotoxic effects (for reviews see references 1 and 2).

Cyclooxygenase (COX; the enzyme that converts arachidonic acid to prostaglandins [PG]) is another critical enzyme in many inflammatory diseases. Two forms of cyclooxygenases have been identified (for reviews see references 3-5). The constitutive isoform (COX-1) is present in tissues such as the stomach, gut, or kidney, where PG production plays a cytoprotective role in maintaining normal physiological processes (for review see reference 3 ). In inflammatory processes, the inducible isoform of cyclooxygenase (COX-2) is expressed in many cells including fibroblasts and macrophages (6-9) and accounts for the release of large quantities of proinflammatory PG at the site of inflammation (for review see references 4 and 5). Production of high levels of proinflammatory PGs can be augmented further in the presence of NO. This effect of NO is probably due to its ability to activate the COX enzyme by an unknown mechanism $(10,11)$. In contrast, the inhibition of high levels of NO production by NOS inhibitors has been found to decrease the production of PG in in vitro and ex vivo models $(10-15)$. These earlier findings allowed us to propose the hypothesis that dual inhibition of proinflammatory NO and PG may contribute to the antiinflammatory properties of NOS inhibitors. The rat air pouch is a convenient model to study acute and chronic inflammation $(16,17)$. This model was therefore used to test our hypothesis.

The results of our studies demonstrate that high levels of NO are produced after the induction of iNOS in the carrageenanstimulated air pouch which contribute significantly to the inflammatory response as well as to the production of a portion of PGs and the cellular infiltration at the site of inflammation. Thus, inhibitors of NOS activity influence the course of inflammation by the dual inhibition of NO and PG and also by inhibiting cellular infiltration.

\section{Methods}

Air pouch model of inflammation. Male Lewis rats weighing 175-200 grams were used throughout this study. Animals were fed normal chow and water ad libitum. Before experimental manipulation, the animals were anesthetized by inhalation of a mixture of $\mathrm{CO}_{2} / \mathrm{O}_{2}(20: 80)$. Air cavities were produced by the subcutaneous injection of $20 \mathrm{ml}$ of sterile air into the intrascapular area of the back. An additional $10 \mathrm{ml}$ of air 
A

IP

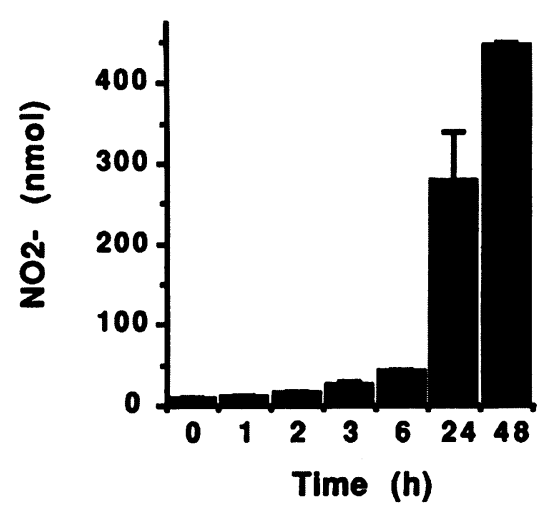

B

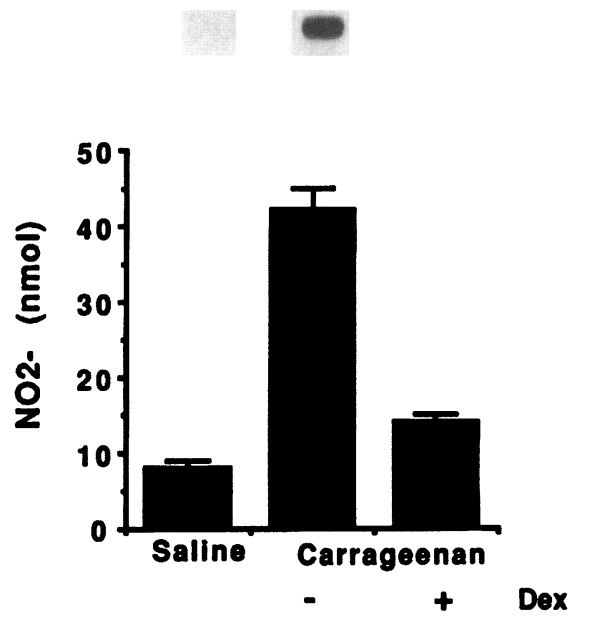

Figure 1. Time-dependent accumulation of $\mathrm{NO}_{2}^{-}$in pouch fluid exudate after carrageenan administration and inhibition of $\mathrm{NO}_{2}^{-}$by dexamethasone. $(A)$ The injection of carrageenan caused a time-dependent increase in $\mathrm{NO}_{2}^{-}$that reached a maximum within $2 \mathrm{~d}$ (bottom, each point is the mean \pm SEM for $n=6$ animals) which correlated with the appearance of iNOS protein as determined by immunoprecipitation (top). $(B)$ The increase in $\mathrm{NO}_{2}^{-}$production observed at $6 \mathrm{~h}$ was completely abolished by dexamethasone $(1 \mathrm{mg} / \mathrm{kg}$ orally, given $1 \mathrm{~h}$ before carrageenan; bottom, each point is the mean \pm SEM for $n=6$ animals). No immunoprecitable iNOS protein was detected in pouch tissue taken from the dexamethasonetreated animals (top). was injected into the cavity every $3 \mathrm{~d}$ to keep the space open. $7 \mathrm{~d}$ after the initial air injection, $2 \mathrm{ml}$ of saline or of a $1 \%$ solution of carrageenan (Sigma Chemical Co., St. Louis, MO) dissolved in saline was injected directly into the pouch (17). Groups of six animals were killed at different time points $(0,3,6,24$, and $48 \mathrm{~h})$ after the injection of saline or carrageenan. The volume of exudate was measured, and the number of leukocytes present in the exudate was determined using a cell counter (Coulter Corp., Hialeah, FL). Differential cell counts were performed using Wright-Giemsa stain. The pouch exudates were assayed for $\mathrm{PGE}_{2}$ by specific ELISAs (Cayman Chemical Co., Ann Arbor, MI) and for $\mathrm{NO}_{2}^{-}$using the diaminonaphthalene assay (18) as markers for COX and NOS activity, respectively. Data were expressed as total amounts of $\mathrm{NO}_{2}^{-}, \mathrm{PGE}_{2}$, or cells. The volume of the pouch fluid in saline-treated animals was $\sim 1 \mathrm{ml}$ and did not change over the 48-h time period; in the carrageenan-treated pouch this volume increased to $3 \mathrm{ml}$ at $3 \mathrm{~h}$ and then remained fairly constant over the 48 -h time period. When inhibitors were tested, compounds were administered twice daily by gavage (p.o., b.i.d.) with the initial treatment $2 \mathrm{~h}$ before the injection of carrageenan; six animals were used for each dose of drug tested.

Colchicine treatment. Animals received a single dose of colchicine ( $1.5 \mathrm{mg} / \mathrm{kg}$, subcutaneously; references 17 and 19) $15 \mathrm{~min}$ before the injection of carrageenan. Rats were killed $6 \mathrm{~h}$ later, and the pouch fluid exudate was assayed for $\mathrm{NO}_{2}^{-}, \mathrm{PGE}_{2}$, leukotriene $\mathrm{B}_{4}$, and cellular infiltration. Colchicine treatment did not affect pouch fluid volume $(3 \pm 0.2$ $\mathrm{ml}$ for carrageenan-injected rats and $3.1 \pm 0.3 \mathrm{ml}$ for carrageenan + colchicine-injected rats, $n=6$ ).

Metabolic labeling with $\left[{ }^{35} \mathrm{~S}\right]$ methionine of cellular pouch exudates and determination of iNOS synthesis by immunoprecipitation. At different time points after carrageenan administration, small pieces of pouch lining tissue were incubated for $4 \mathrm{~h}$ in methionine-free DME containing $\left[{ }^{35} \mathrm{~S}\right]$ methionine $(0.1 \mathrm{mCi} /$ well, $10 \mathrm{mCi} / \mathrm{ml}$; Amersham Corp., Arlington Heights, IL). Cells from the fluid exudate were also collected, separated by centrifugation, and plated into $35-\mathrm{mm}$ plastic culture dishes. After a 30-min preincubation in methionine-free DME, the cells were incubated in the same medium containing $\left[{ }^{35} \mathrm{~S}\right]$ methionine as described above. Solubilization and immunoprecipitation of the iNOS and COX-2 enzyme were performed as described previously using specific antibodies that recognized either iNOS or COX-2 $(20,21)$.

Immunohistochemical localization of iNOS. Immunohistochemical staining for iNOS was performed on cytospin preparations of cells $(40,000 \mathrm{cells} / \mathrm{slide})$ isolated from the pouch exudate and on $10-\mu \mathrm{m}$ frozen sections of pouch lining tissues. Before preparing the cytospins, dead cells and debris were removed by centrifuging the cells at $300 \mathrm{~g}$ for $10 \mathrm{~min}$ through a layer of fetal bovine serum. Additionally, the cells obtained from the carrageenan pouch fluid were enriched for mononuclear cells from $\sim 2-12 \%$ by separation using Ficoll-Hypaque. Cells

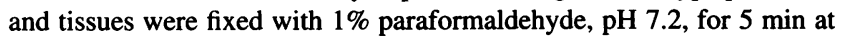

room temperature, followed by $100 \%$ ethanol, $5 \mathrm{~min}$ at $4^{\circ} \mathrm{C}$. Nonspecific staining was blocked with $3 \%$ normal goat serum in $0.5 \mathrm{M}$ Tris- $\mathrm{HCl}$, $\mathrm{pH} \mathrm{7.4,} \mathrm{containing} 1 \%$ Triton $\mathrm{X}-100$ for $1 \mathrm{~h}$ at room temperature. All subsequent incubations were carried out in this buffer. Cells and tissue sections were incubated for $16 \mathrm{~h}$ at $4^{\circ} \mathrm{C}$ with a $1: 1,000$ dilution of either preimmune rabbit sera or the anti-iNOS antiserum described above. Endogenous peroxidase activity was then reduced with periodic acid (Zymed Laboratories, Inc., South San Francisco, CA) for $45 \mathrm{~s}$ at room temperature followed by sequential incubations with biotinylated antirabbit IgG and avidin-biotin-peroxidase complex (ABC; Vector Laboratories, Inc., Burlingame, $\mathrm{CA}$ ) for $2 \mathrm{~h}$ each. The reaction product was visualized using 3,3'-diaminobenzidine intensified with nickel chloride for $6 \mathrm{~min}$. Cells and tissue sections were counterstained with Mayer's hematoxylin, mounted, and photographed using either Hoffman modulation optics or bright field microscopy.

Histology. Pouch tissue lining from saline- and carrageenan-treated rats was dissected free of underlying tissue and fixed in $10 \%$ neutral buffered formalin. Tissues were then embedded in paraffin, sectioned, and stained with hematoxylin and eosin.

Blood pressure measurements. To determine the effects of the inhibitors on hemodynamic parameters, blood pressure measurements were performed both before and after drug administration using a IITC tail cuff blood pressure machine (Life Science Instruments, Woodland Hills, CA).

Statistical analysis. Results are expressed as mean \pm SEM for ( $n$ ) animals. The results were analyzed by Student's unpaired $t$ test to determine the significant difference between means, or by a two-way ANOVA followed by a least significance procedure to determine the nature of this response. A $P$ value of $<0.05$ was considered significant.

Materials. Male Lewis rats were purchased from Harlan SpragueDawley (Indianapolis, IN). All animal protocols were approved by the Institutional Animal Care and Use Committee and were in accordance with National Institutes of Health guidlines on laboratory animal welfare. 2,3-Diaminonaphthalene was purchased from Aldrich (Milwaukee, WI). All other chemicals and reagents were obtained from Sigma Chemical Co. $N$-iminoethyl-L-lysine (L-NIL) was synthesized in house as described previously (20).

\section{Results}

Time-dependent increase in $\mathrm{NO}_{2}^{-}, \mathrm{PGE}_{2}$, and cellular infiltration in the inflamed air pouch exudate. Carrageenan induced a time-dependent increase in $\mathrm{NO}_{2}^{-}$in the pouch exudate fluid (Fig. $1 \mathrm{~A}$ ); this effect was observed within $3 \mathrm{~h}$ and continued to increase during the 48-h time course studied. The increase in $\mathrm{NO}_{2}^{-}$accumulation in the carrageenan-treated pouch is likely 

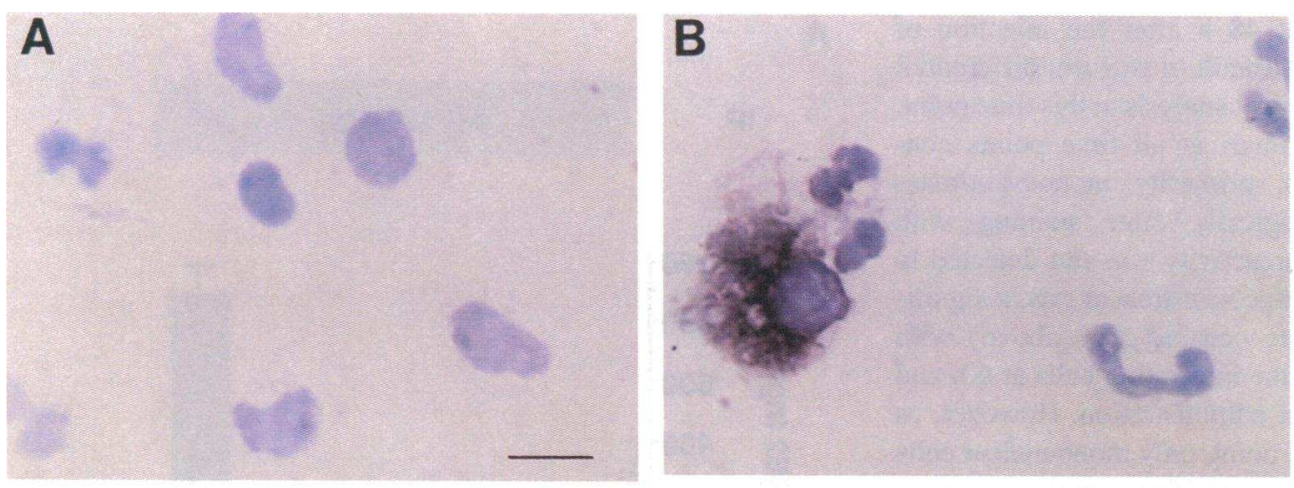

Figure 2. Immunohistochemical staining of iNOS in the carrageenan-induced rat air pouch. ( $A$ and $B$ ) Immunohistochemical staining of iNOS protein in cells from fluid exudates were obtained from control and carrageenantreated rats. Cells were collected from the pouch exudates, centrifuged, fixed, and stained for iNOS using a specific antipeptide anti-
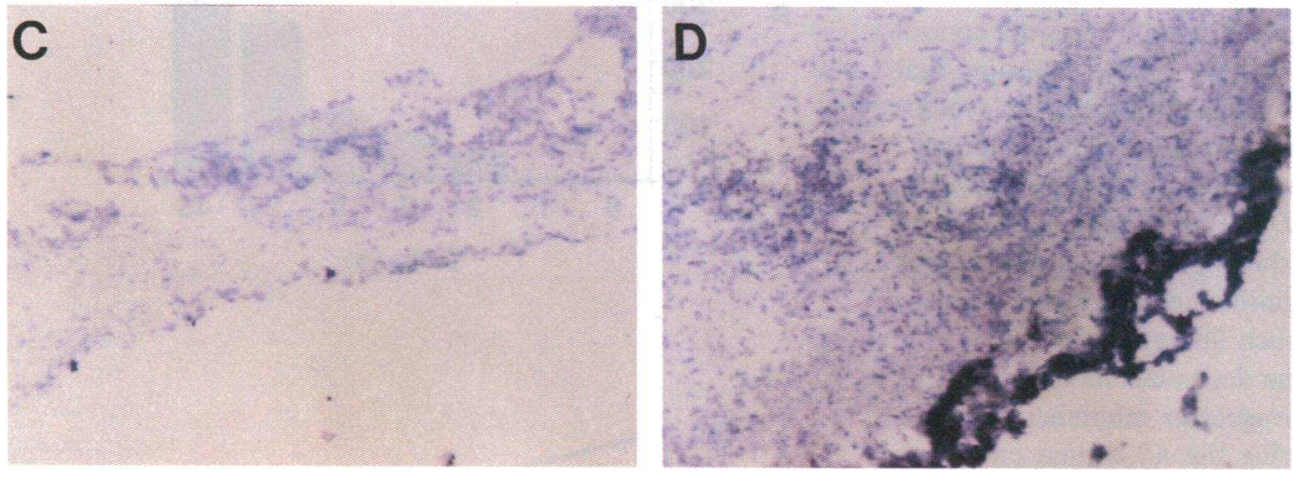
body. $(A)$ Cells from a control pouch; $(B)$ cells from carrageenan-treated rats; positive staining was found in macrophages (identified morphologically) but not in PMNs. ( $C$ and $D$ ) Staining of $\mathrm{iNOS}$ in pouch lining from control and carrageenan-treated rats. Frozen sections from the pouch linings were fixed and stained as above. (C) Control pouch; (D) carrageenan-treated pouch tissue with positive staining of iNOS in the inner layer of the tissue.

due to the activity of iNOS. Indeed, immunoprecipitation of pouch tissue with antibodies generated against iNOS indicated that iNOS protein was detected at $2 \mathrm{~h}$ after carrageenan, was maximal at $6 \mathrm{~h}$, and then its synthesis tended to decline by 48 $\mathrm{h}$ (Fig. $1 \mathrm{~A}$ ). $\mathrm{NO}_{2}^{-}$synthesis in the pouch exudate from salinetreated animals did not change, remaining at a basal level of $8 \pm 1 \mathrm{nmol}(n=12)$.

Carrageenan administration also caused a time-dependent accumulation of leukocytes in the exudate (from $0.9 \pm 0.03$ $\times 10^{6}$ leukocytes at time 0 to $50 \pm 4,67 \pm 3,81 \pm 11$, and $342 \pm 51$ $\times 10^{6}$ leukocytes at $3,6,24$, and $48 \mathrm{~h}$ after the administration of carrageenan). Cytospin preparations of cells obtained in the fluid exudate as well as frozen sections of pouch lining at 0 and $6 \mathrm{~h}$ after carrageenan injection were analyzed immunohistochemically to identify the cell type that expressed iNOS and COX-2. The high degree of cellular degranulation and cell death
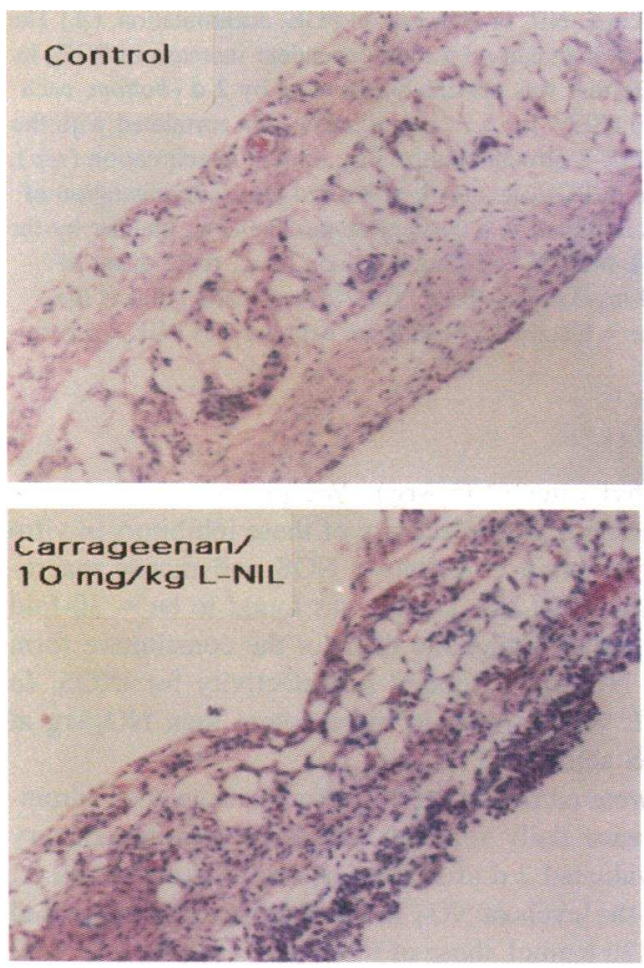
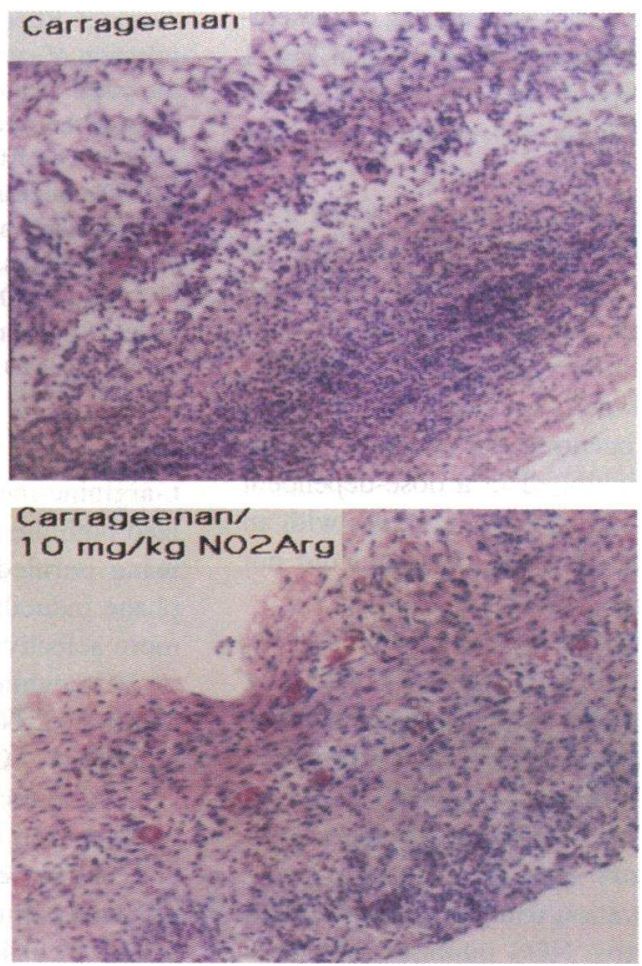

Figure 5. Histology of the inflamed pouch after treatment with L-NIL or $\mathrm{NO}_{2} \mathrm{Arg}$. Pouch tissues were taken from saline-treated an imals (Control), $2 \mathrm{~d}$ after carrageenan, $2 \mathrm{~d}$ after carrageenan in rats treated with L-NIL, and $2 \mathrm{~d}$ after carrageenan in rats treated with $\mathrm{NO}_{2} \mathrm{Arg}(10 \mathrm{mg} / \mathrm{kg})$. 
observed in the fluid exudate at $48 \mathrm{~h}$ after the injection of carrageenan made it technically difficult to perform differential cell counts and immunohistochemical analysis at this time point. Exudates from saline-treated animals at all time points contained small numbers of cells, primarily monocytes/macrophages determined morphologically after staining with Wright's-Giemsa. iNOS immunoreactivity was not detected in these cells (Fig. $2 \mathrm{~A}$ ). In the carrageenan-treated rats, a significant increase in cellular infiltrate occured (see above) with PMNs accounting for $>98 \%$ of the infiltrating cells at $6 \mathrm{~h}$ and of $85 \%$ at $24 \mathrm{~h}$ after carrageenan administration. However, as shown in Fig. $2 B$ for the 6-h time point, only mononuclear cells in the exudate but not PMNs contained iNOS immunoreactivity. Immunohistochemical analysis of the pouch lining of control animals showed no iNOS staining (Fig. $2 C$ ), suggesting that detectable iNOS enzyme was not induced during the development of the pouch tissue lining. In contrast, carrageenan induced the expression of iNOS-like immunoreactivity in cells of the inflamed pouch lining (Fig. $2 \mathrm{D}$ ). Based upon morphology and ED1 positive staining (not shown), iNOS induction was localized primarily to macrophage-like cells present in the superficial layer of the inflamed pouch lining.

Carrageenan also elicited a time-dependent increase in $\mathrm{PGE}_{2}$ production within $2 \mathrm{~h}$ after carrageenan administration and which continued to increase during the 48-h time course of the experiment (Fig. $3 \mathrm{~A}$ ). COX-2 protein synthesis was also measurable by $2 \mathrm{~h}$, was maximal after $6 \mathrm{~h}$, and remained elevated for up to $48 \mathrm{~h}$ after carrageenan administration (Fig. $3 A$ ).

Effects of dexamethasone on $\mathrm{NO}_{2}^{-}, \mathrm{PGE}_{2}$, and cellular infiltration. Glucocorticoids such as dexamethasone affect NO biosynthesis in vitro and in vivo by inhibiting the expression of iNOS without affecting cNOS synthesis or activity (22-24). The increase in $\mathrm{NO}_{2}^{-}$observed $6 \mathrm{~h}$ after carrageenan administration was inhibited by dexamethasone in a dose-dependent manner from $42 \pm 3 \mathrm{nmol} \mathrm{NO}_{2}^{-}$for carrageenan alone to $38 \pm 7$, $20 \pm 1$, and $14 \pm 1 \mathrm{nmol} \mathrm{NO}_{2}^{-}$for, respectively, carrageenan administered in combination with $0.01,0.1$, or $1 \mathrm{mg} / \mathrm{kg}$ dexamethasone, p.o., b.i.d. ( $n=6$ animals/group). As shown in Fig. 1 $B$, no immunoprecitable iNOS protein was detected in pouch tissue from animals that received $1 \mathrm{mg} / \mathrm{kg}$ dexamethasone $1 \mathrm{~h}$ before carrageenan stimulation.

Dexamethasone also inhibits the induction of COX-2 in vitro and in vivo without affecting COX-1 (for reviews see references 4 and 5). As expected, the increase in $\mathrm{PGE}_{2}$ release was inhibited in a dose-dependent manner by dexamethasone (46 $\pm 3,53 \pm 5$, and $99 \pm 2 \%$ inhibition with, respectively, 0.01 , 0.1 , and $1 \mathrm{mg} / \mathrm{kg}$, p.o., $n=6$ ). Finally and as shown in Table I, the cellular infiltration which occurred during the $2 \mathrm{~d}$ after carrageenan administration was inhibited in a dose-dependent manner by dexamethasone $(0.01-1 \mathrm{mg} / \mathrm{kg}$, p.o., b.i.d.) with an $\mathrm{IC}_{50}$ value of $0.04 \mathrm{mg} / \mathrm{kg}$. Dexamethasone treatment did not affect the basal levels of $\mathrm{NO}_{2}^{-}$and $\mathrm{PGE}_{2}$ (not shown).

In summary, the results shown in Figs. 1-3 indicate that iNOS and COX-2 are expressed in the inflamed air pouch after the administration of carrageenan and subsequently accounted for the large production of $\mathrm{NO}_{2}^{-}$and $\mathrm{PG}$ observed in this model.

Effects of NOS inhibitors ( $\mathrm{L}-\mathrm{NIL}$ and $\mathrm{NO}_{2} \mathrm{Arg}$ ) on $\mathrm{NO}_{2}^{-}$, $P G E_{2}$, and cellular infiltration. We next examined the role of NO in producing the inflammatory changes occurring in the pouch after carrageenan administration using a selective iNOS inhibitor, L-NIL, and a nonselective NOS inhibitor, $N^{\mathrm{G}}$-nitro-
A

IP
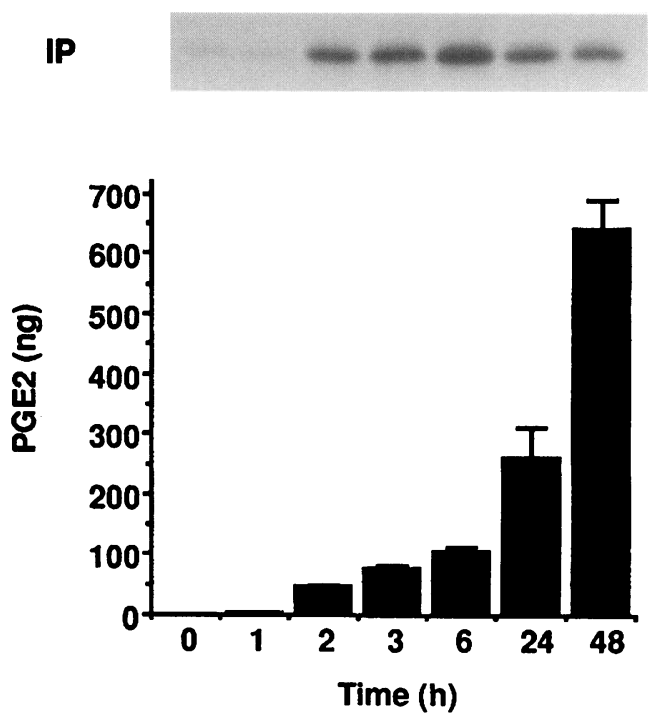

B

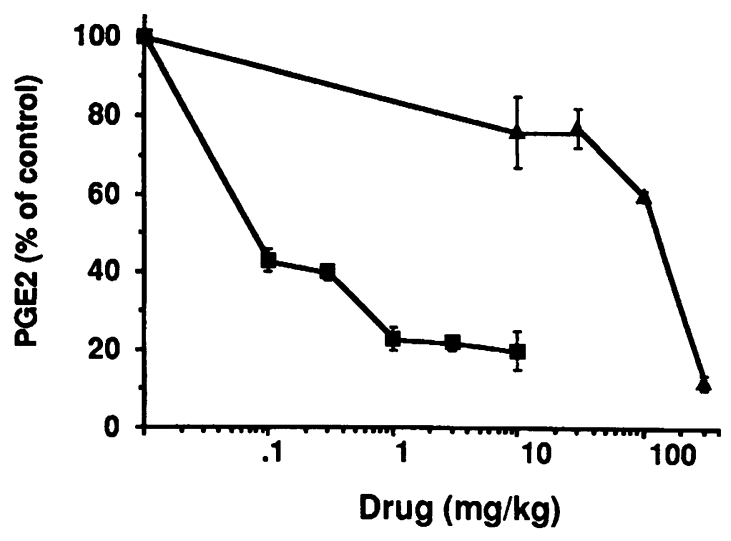

Figure 3. Effects of L-NIL or $\mathrm{NO}_{2} \mathrm{Arg}$ on $\mathrm{PGE}_{2}$ accumulation. $(A)$ The injection of carrageenan caused a time-dependent increase in $\mathrm{PGE}_{2}$ in the pouch exudate that was maximally elevated by $2 \mathrm{~d}$ (bottom, each point is the mean \pm SEM for $n=12$ animals); this correlated with the appearance of COX-2 protein analyzed by immunoprecipitation (top). $(B)$ The increase in $\mathrm{PGE}_{2}$ levels observed $2 \mathrm{~d}$ after administration of carrageenan was inhibited in a concentration-dependent manner by the NOS inhibitors, L-NIL $(0.1-10 \mathrm{mg} / \mathrm{kg}$, p.o., b.i.d., for $2 \mathrm{~d}, \boldsymbol{\square})$ or $\mathrm{NO}_{2} \mathrm{Arg}(1-300 \mathrm{mg} / \mathrm{kg}$, p.o., b.i.d., for $2 \mathrm{~d}, \Delta)$. Each point is the mean \pm SEM for $n=6$ animals. Results are expressed as $\mathrm{PGE}_{2}$ (percentage of control).

L-arginine-methyl ester $\left(\mathrm{NO}_{2} \mathrm{Arg}\right)$. We previously characterized both the potency and selectivity of these inhibitors in vitro using purified rat brain constitutive NOS and mouse macrophage inducible NOS (25). L-NIL was found to be $\sim 30$-fold more selective for the inducible than for the constitutive form of NOS while $\mathrm{NO}_{2} \mathrm{Arg}$ exhibited no selectivity for iNOS. In addition, L-NIL was $\sim 6.5$-fold more potent than $\mathrm{NO}_{2} \mathrm{Arg}$ at inhibiting iNOS activity (25).

Inhibitors were administered $2 \mathrm{~h}$ before carrageenan administration and twice daily for $2 \mathrm{~d}$, and their antiinflammatory effects were evaluated $2 \mathrm{~d}$ after carrageenan administration. At this time point, the levels of $\mathrm{NO}_{2}^{-}$in the pouch exudate increased from $8 \pm 1$ to $442 \pm 6 \mathrm{nmol}$, those of $\mathrm{PGE}_{2}$ increased from $1 \pm 0.02$ 
Table I. Effects of Dexamethasone and NOS Inhibitors on Cellular Infiltration in the Pouch Exudate after Carrageenan

\begin{tabular}{cccc}
\hline & \multicolumn{3}{c}{ Percent cell accumulation } \\
\cline { 2 - 4 } Dose & Dexamethasone & L-NIL & NO $_{2}$ Arg \\
\hline$m g / k g$ & & & \\
0 & 100 & 100 & 100 \\
0.01 & $85 \pm 3$ & 100 & \\
0.1 & $40 \pm 2$ & $82 \pm 3$ & \\
0.3 & $\mathrm{ND}$ & $70 \pm 2$ & 100 \\
1 & $10 \pm 2$ & $69 \pm 3$ & $75 \pm 2$ \\
3 & $\mathrm{ND}$ & $53 \pm 2$ & $57 \pm 3$ \\
10 & $7 \pm 1$ & $26 \pm 3$ & $46 \pm 2$ \\
30 & & $15 \pm 2$ & $34 \pm 2$ \\
100 & & & $30 \pm 2$ \\
300 & & &
\end{tabular}

The large accumulation of leukocytes seen $2 \mathrm{~d}$ after carrageenan injection was inhibited in a dose-dependent fashion by dexamethasone, $\mathrm{L}-$ $\mathrm{NIL}$, or $\mathrm{NO}_{2} \mathrm{Arg}$ (drugs were given orally for two consecutive days). Results are expressed as percent cell accumulation when compared with cell accumulation obtained in the presence of carrageenan alone. Each point is the mean \pm SEM for $n=6$ animals.

to $642 \pm 50 \mathrm{ng}$, and the number of infiltrating leukocytes increased from $0.9 \pm 0.03$ to $342 \pm 51 \times 10^{6}$ cells. Fig. 4 shows that this marked increase in $\mathrm{NO}_{2}^{-}$was inhibited in a dose-dependent fashion by L-NIL ( IC $_{50}=0.7 \mathrm{mg} / \mathrm{kg}, n=6$ ) or $\mathrm{NO}_{2} \mathrm{Arg}$ $\left(\mathrm{IC}_{50}=9.8 \mathrm{mg} / \mathrm{kg}, n=6\right)$. Interestingly, accumulation of $\mathrm{PGE}_{2}$ in the pouch exudate was also inhibited in a dose-dependent manner by L-NIL $\left(\mathrm{IC}_{50}=0.2 \mathrm{mg} / \mathrm{kg}\right)$ or $\mathrm{NO}_{2} \mathrm{Arg}\left(\mathrm{IC}_{50}=1.8\right.$ $\mathrm{mg} / \mathrm{kg}$ ) (Fig. $3 B$ ). Finally, cellular infiltration was also inhibited by the NOS inhibitors $\left(\mathrm{IC}_{50}=2.9 \mathrm{mg} / \mathrm{kg}\right.$ for L-NIL and $8.5 \mathrm{mg} / \mathrm{kg}$ for $\mathrm{NO}_{2} \mathrm{Arg}$ ) (Table I). $\mathrm{NO}_{2} \mathrm{Arg}$ or L-NIL had no effect on the volume of pouch fluid $(3 \pm 0.4 \mathrm{ml}$ for carrageenaninjected rats and $2.8 \pm 0.4$ and $3 \pm 0.2 \mathrm{ml}$ for carrageenan-injected rats that received either 30 or $10 \mathrm{mg} / \mathrm{kg} \mathrm{NO} \mathrm{N}_{2} \mathrm{Arg}$ or L-NIL, p.o., b.i.d., respectively, $n=6$ ).

To assess the antiinflammatory effects of the NOS inhibitors, the pouch lining was also examined histologically. As shown in Fig. 5, the noninflamed, control pouch lining tissue consists of a layer of flattened cells overlying loose vascular connective tissue. Macrophages and fibroblasts comprise the inner layer of flattened cells (16). $2 \mathrm{~d}$ after carrageenan administration, marked inflammatory changes were observed including pronounced cellular infiltration and edema (evidenced by the thickening of the tissue). Treatment with the selective iNOS inhibitor, L-NIL ( $10 \mathrm{mg} / \mathrm{kg}$, p.o., b.i.d.), significantly reduced these changes such that minimal edema and cellular infiltration were seen. $\mathrm{NO}_{2} \mathrm{Arg}(10 \mathrm{mg} / \mathrm{kg}$, p.o., b.i.d.) also reduced the inflammatory changes although to a lesser extent than L-NIL. The potency of these compounds at inhibiting the histological changes (at the highest doses used) correlated well with their ability to inhibit $\mathrm{NO}_{2}^{-}$and $\mathrm{PGE}_{2}$ production and cellular infiltration. At these doses, L-NIL caused a 97, 80, and 93\% reduction in $\mathrm{NO}_{2}^{-}, \mathrm{PGE}_{2}$, and cell infiltration, respectively $(n=6)$, whereas $\mathrm{NO}_{2} \mathrm{Arg}$ caused a 58,26 , and $54 \%$ reduction in $\mathrm{NO}_{2}^{-}, \mathrm{PGE}_{2}$, and cell infiltration, respectively, in the pouch fluid exudate $(n=6)$. Therefore, L-NIL appears to be a more potent antiinflammatory agent than $\mathrm{NO}_{2} \mathrm{Arg}$ as assessed in this inflammatory model.

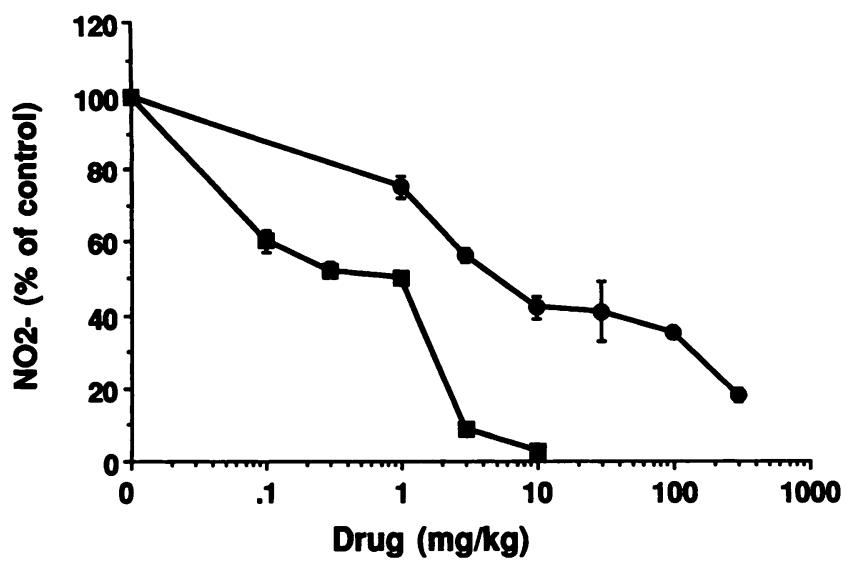

Figure 4. Effects of NOS inhibitors on nitrite accumulation in the air pouch. The increase in $\mathrm{NO}_{2}^{-}$levels observed in the air pouches after a 2-d treatment with carrageenan was inhibited in a concentration-dependent manner by the NOS inhibitors, L-NIL $(0.1-10 \mathrm{mg} / \mathrm{kg}$ orally for $2 \mathrm{~d}, \boldsymbol{\omega})$ or $\mathrm{NO}_{2} \mathrm{Arg}(1-300 \mathrm{mg} / \mathrm{kg}$ orally for $2 \mathrm{~d}, \bullet)$. Results are expressed as $\mathrm{NO}_{2}^{-}$(percentage of control). Each point is the mean \pm SEM for $n=6$ animals.

Effects of $\mathrm{NS} 398$ on $\mathrm{NO}_{2}^{-}, \mathrm{PGE}_{2}$, and cellular infiltration. NS398, a selective COX-2 inhibitor $(21,26,27)$, has been described recently as a potent antiinflammatory agent (21). Consistent with this finding, we found that the increase in $\mathrm{PGE}_{2}$ production after carrageenan administration was inhibited by NS398 (by $78 \pm 6,74 \pm 4$, and $92 \pm 3 \%$ with $0.1,1$, and $10 \mathrm{mg} /$ $\mathrm{kg}$, p.o., b.i.d., respectively, $n=6$ ). However, there was no correlation between the ability of NS398 to inhibit $\mathrm{PGE}_{2}$ production and its ability to inhibit $\mathrm{NO}_{2}^{-}$levels and cellular infiltration. Thus, when compared with $\mathrm{PGE}_{2}$ inhibition, NS398 produced only a small inhibition of $\mathrm{NO}_{2}^{-}$production $(11 \pm 1,16 \pm 8$, and $28 \pm 8 \%$ with $0.1,1$, and $10 \mathrm{mg} / \mathrm{kg}$, p.o., b.i.d., respectively, $n=6)$ and cellular infiltration $(4 \pm 1,1 \pm 0.4$, and $10 \pm 6 \%$ with $0.1,1$, and $10 \mathrm{mg} / \mathrm{kg}$, p.o., b.i.d., respectively, $n=6$ ).

Effects of colchicine on $\mathrm{NO}_{2}^{-}, \mathrm{PGE}_{2}$, and cellular infiltration. To determine whether the elevated $\mathrm{NO}_{2}^{-}$and $\mathrm{PGE}_{2}$ concentrations in the pouch fluid exudate were dependent upon leukocyte infiltration, colchicine was used to prevent cellular infiltration into the exudate $(17,19)$. Analysis was performed only at the 6-h time point after carrageenan administration since at later time points colchicine was found to have toxic effects. Colchicine was given subcutaneously as a single dose $(1.5 \mathrm{mg} /$ kg) $15 \mathrm{~min}$ before carrageenan administration. Animals were killed $6 \mathrm{~h}$ later. Colchicine reduced cellular infiltration into the pouch fluid exudate by $98 \%$ ( $n=6$ animals ), but did not inhibit either $\mathrm{NO}_{2}^{-}$or $\mathrm{PGE}_{2}$ production (Fig. 6). In contrast, colchicine inhibited by at least $88 \%$ the increased production of leukotriene $\mathrm{B}_{4}$ that occurred $6 \mathrm{~h}$ after the administration of carrageenan (from $0.06 \pm 0.008$ to $0.8 \pm 0.03$ and $0.1 \pm 0.01 \mathrm{ng} / \mathrm{ml}, n=6$, for, respectively, levels of leukotriene $B_{4}$ before carrageenan, $6 \mathrm{~h}$ after carrageenan, and $6 \mathrm{~h}$ after carrageenan in animals treated with colchicine).

Hemodynamic effects. The selective iNOS inhibitor, L-NIL, had no effect on blood pressure at the highest dose tested (30 $\mathrm{mg} / \mathrm{kg}$, p.o., b.i.d., for $2 \mathrm{~d}$; from $101 \pm 3$ to $97 \pm 14 \mathrm{mmHg}, n$ $=4$ ), indicating that it did not markedly affect the activity of constitutive NOS. In contrast and as expected, treatment with the nonselective NOS inhibitor, $\mathrm{NO}_{2} \mathrm{Arg}(300 \mathrm{mg} / \mathrm{kg}$, p.o., b.i.d., for $2 \mathrm{~d}$ ), caused a significant increase in mean arterial 

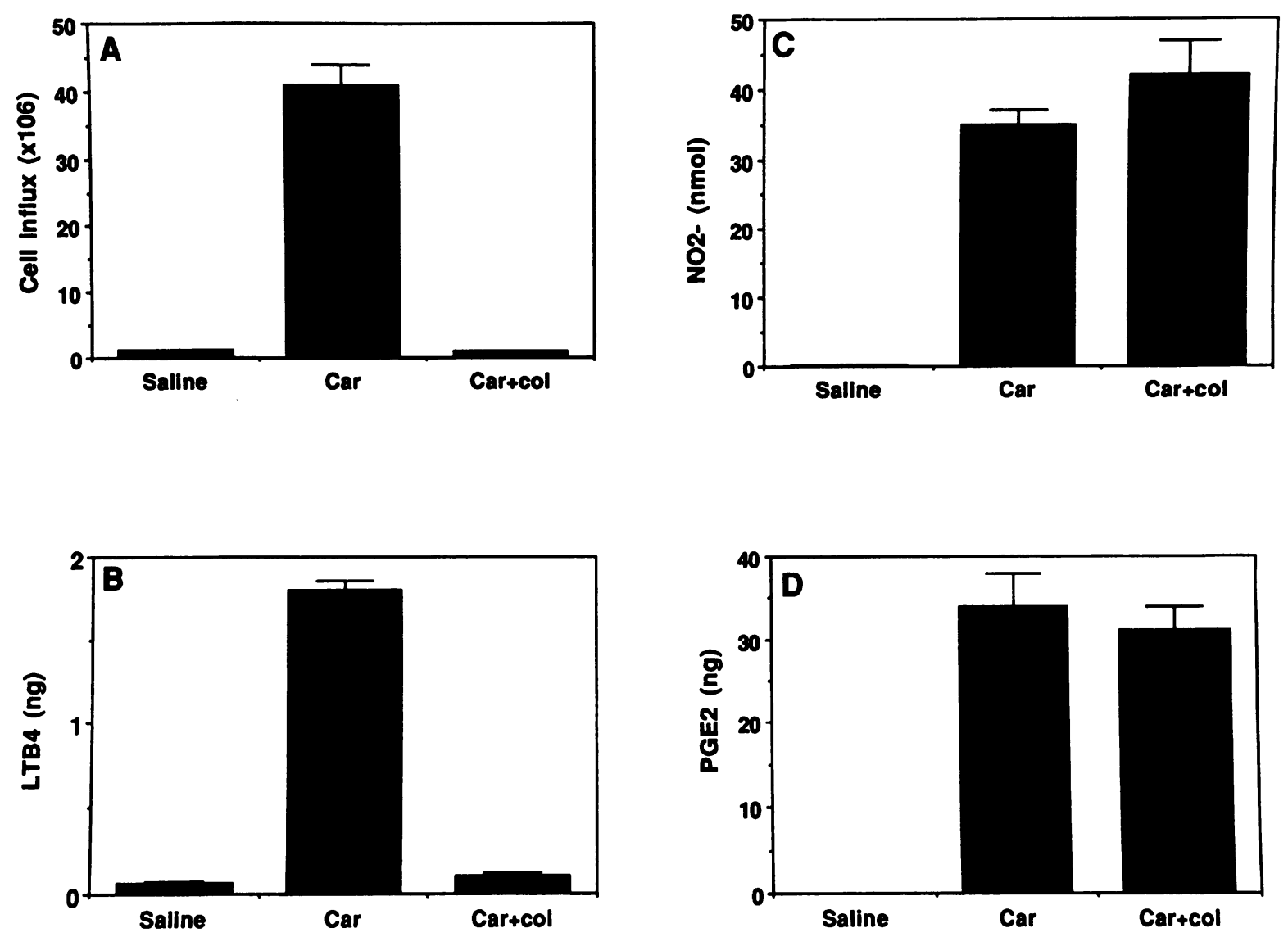

Figure 6. The effect of colchicine (col) on cell accumulation, $\mathrm{NO}_{2}^{-}, \mathrm{PGE}_{2}$, and leukotriene $\mathrm{B}_{4}$ (LTB4) elicited by the injection of carrageenan ( Car $)$ in the rat air pouch. Colchicine inhibited cell infiltration $(A)$ and leukotriene $\mathrm{B}_{4}(B)$ levels but failed to alter the concentration of NO${ }_{2}^{-}(C)$ and $\mathrm{PGE}_{2}(D)$. Each point is the mean $\pm \mathrm{SEM}$ for 6 animals.

blood pressure (from $101 \pm 3$ to $141 \pm 5 \mathrm{mmHg}, n=4$ ). Blood pressure was not affected by $2 \mathrm{~d}$ of treatment with the highest dose of NS398 (10 mg/kg, p.o., b.i.d., from $101 \pm 3$ to $114 \pm 5$ $\mathrm{mmHg}, n=4)$ or dexamethasone ( $10 \mathrm{mg} / \mathrm{kg}$, p.o., b.i.d., from $101 \pm 3$ to $100 \pm 3 \mathrm{mmHg}, n=4)$.

\section{Discussion}

The experiments performed in this study were designed to test the following hypothesis: does the dual inhibition of proinflammatory nitric oxide and prostaglandin contribute to the antiinflammatory properties of NOS inhibitors?

A rapid induction of iNOS protein was observed in the inflamed pouch lining and cells from fluid exudates. Production of high levels of $\mathrm{NO}_{2}^{-}$in the pouch exudate fluid as a result of carrageenan induction coincided with the expression of iNOS protein. The contribution of iNOS in producing the inflammatory changes after carrageenan administration was further supported by the findings that $(a)$ dexamethasone, a glucocorticoid that inhibits iNOS expression in vitro and in vivo without affecting cNOS $(1,22)$, blocked iNOS protein expression and completely suppressed $\mathrm{NO}_{2}^{-}$synthesis, and that $(b)$ L-NIL, a recently described iNOS inhibitor (25), prevented the production of $\mathrm{NO}_{2}^{-}$elicited by carrageenan. In addition, iNOS-like immunoreactivity was localized to macrophages, but not to PMNs, suggesting that these cell types are the source of iNOS-derived $\mathrm{NO}_{2}^{-}$. Basal levels of $\mathrm{NO}_{2}^{-}$were very small and were not af- fected by dexamethasone or L-NIL. Taken together these observations suggest that induction of iNOS, presumably in macrophages, is responsible for the large release of NO and that cNOS activity does not make a significant contribution to the NO formation in this model of inflammation. Induction of COX-2 in macrophages, but not infiltrating neutrophils, also appears to be responsible for the increased PG levels in this model (21).

We have recently reported in in vitro studies that NO activates COX-2, resulting in large production of PG $(10,12)$, a finding that has now being substantiated in a number of other systems $(11,13-15)$. As shown in this paper, induction of iNOS with the subsequent release of NO appears to enhance the production of $\mathrm{PGE}_{2}$ at the site of inflammation. Indeed, when endogenous NO production was inhibited with L-NIL, the increased production in $\mathrm{PGE}_{2}$ observed after the injection of carrageenan was markedly reduced. This effect is not due to a direct inhibition of the NOS inhibitor on COX activity or PG isomerase activity $(10,28)$. Therefore, modulation of the COX system by NO represents an important pathway that regulates the extent of the inflammatory process. In contrast, our results indicate that selective inhibition of COX-2 and hence PG production had only a minor effect on $\mathrm{NO}_{2}^{-}$production consistent with our previous observations in vitro $(10,12)$. The lack of significant inhibition of $\mathrm{NO}_{2}^{-}$production by a cyclooxygenase inhibitor supports the hypothesis that the overall inhibition of the inflammatory process by NOS inhibitors is not sufficient to explain their marked inhibitory effects on PG production. 


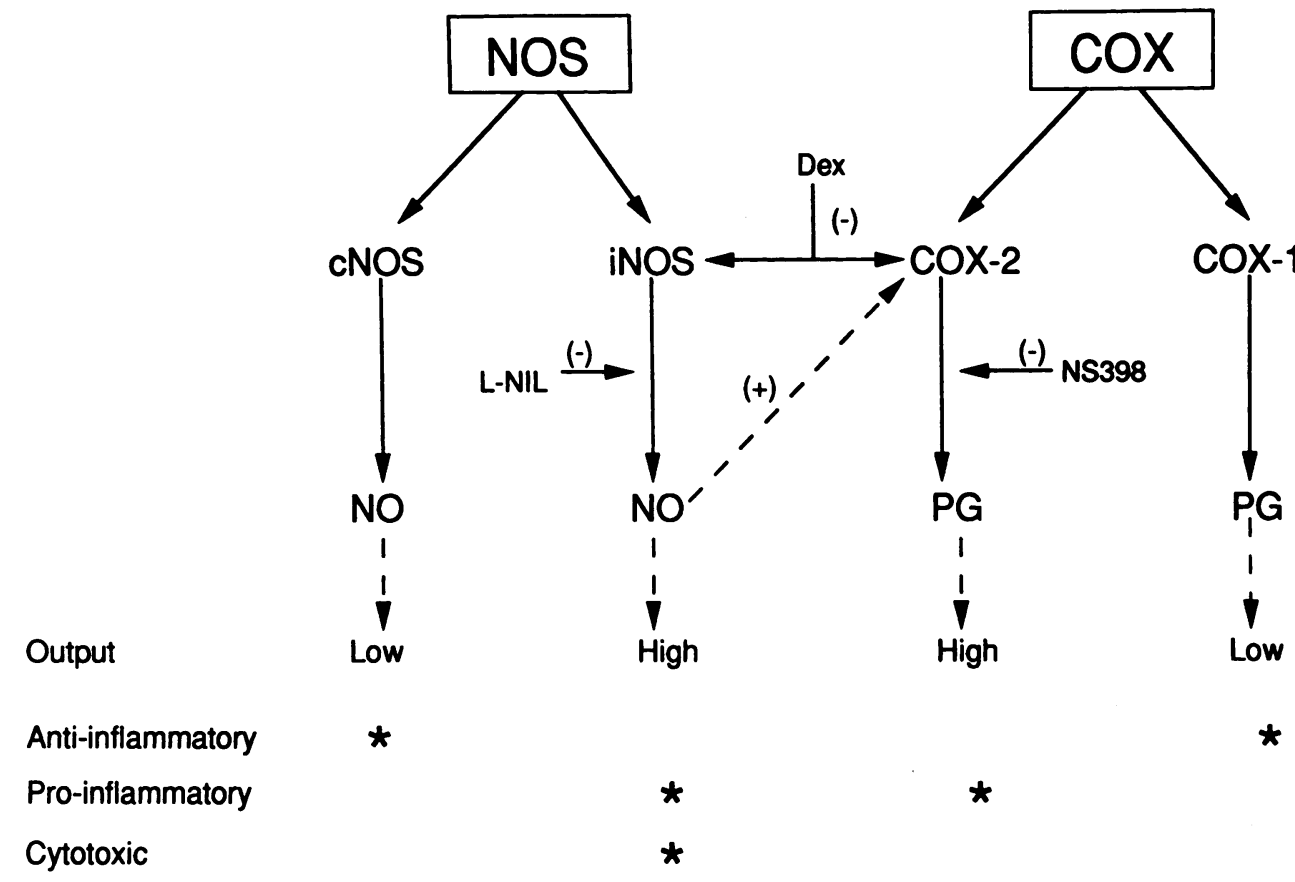

Figure 7. Proposed model of the interactions between the NO and COX pathway in inflammation.

The inflammatory response that occurs after the injection of carrageenan in the air pouch is also characterized by cellular infiltration (references 16 and 17 and this paper). Neutrophils account for $>98$ and $85 \%$ of the infiltrating cells at 6 and 24 $\mathrm{h}$, respectively, after carrageenan. In contrast, monocytes in the pouch fluid comprised 2 and $15 \%$ at 6 and $24 \mathrm{~h}$, respectively, after carrageenan $(16,21)$. Table I shows that the large increase in cellular infiltration at $\mathbf{4 8} \mathrm{h}$ after carrageenan was attenuated by either dexamethasone or L-NIL. Since we could not perform accurate cell differential at $48 \mathrm{~h}$ after carrageenan due to the cellular deterioration (see Methods), we could not determine whether dexamethasone or L-NIL affected the distribution of neutrophil/monocyte infiltration at this time point. Nevertheless, inhibition of cellular infiltration by dexamethasone or L-NIL may well contribute to the overall antiinflammatory effects of these drugs.

To determine whether the increasing $\mathrm{NO}_{2}^{-}$and $\mathrm{PG}$ in the exudate was a consequence of neutrophils infiltration or was produced by resident pouch lining cells, colchicine was used to block the cellular influx into the exudate. Our results suggest that neutrophil infiltration does not significantly contribute to $\mathrm{NO}_{2}^{-}$and $\mathrm{PGE}_{2}$ production in the fluid exudate early in the inflammatory response $(6 \mathrm{~h})$. Colchicine blocked neutrophil infiltration by $99 \%$, but did not inhibit the 5 - and 100 -fold increases in $\mathrm{NO}_{2}^{-}$or PG production which occurred after $6 \mathrm{~h}$ after carrageenan administration. This is substantiated further by the finding that iNOS-like immunoreactivity was not localized to neutrophils. In contrast, the infiltrating neutrophils are the source for the elevated leukotriene $B_{4}$ levels in the fluid exudate, as the leukotriene $B_{4}$ levels were markedly attenuated by the colchicine treatment. At the early time point, $\mathrm{NO}_{2}^{-}$and $\mathrm{PGE}_{2}$ are most likely formed by cells comprising the pouch lining tissue. However, at the later stages of the inflammation $(48 \mathrm{~h})$, the elevated production of NO/PG may be produced not only by resident macrophages/fibroblasts in the pouch lining but also by infiltrating monocytes.

When the effects of L-NIL were compared with those of the nonselective cNOS/iNOS inhibitor $\mathrm{NO}_{2} \mathrm{Arg}$ (29), we found that $\mathrm{NO}_{2} \mathrm{Arg}$ decreased $\mathrm{NO}_{2}^{-}$and $\mathrm{PGE}_{2}$ production and cellular infiltration, but to a lesser extent than L-NIL. This is consistent with the fact that L-NIL is a more potent inhibitor of iNOS activity than $\mathrm{NO}_{2} \mathrm{Arg}$ in vitro (25). This greater antiinflammatory effect of L-NIL versus $\mathrm{NO}_{2} \mathrm{Arg}$ was also observed histologically. Thus, both the leukocytic infiltration into the tissue as well as the edema were reduced to a much greater extent in the L-NIL-treated animals as compared with those treated with $\mathrm{NO}_{2}$ Arg. Although infiltrating neutrophils are not responsible for the increased production of proinflammatory NO and PG, their inhibition at the inflamed site by the NOS inhibitors could very well contribute to the antiinflammatory effects of the NOS inhibitors. It is well known that neutrophils release a variety of mediators and enzymes endowed with proinflammatory properties.

The importance of our findings is highlighted in the model shown in Fig. 7. The induction of iNOS and COX-2 by mediators of inflammation such as endotoxin or cytokines occurs in a number of diseases and results in the elevated production of the proinflammatory mediators, NO and PG. Furthermore, the functional interaction between the NOS and COX pathways in inflammation suggests that NO may exacerbate the inflammatory process through the generation of additional proinflammatory PG. Regulation of COX by NO may also depend on the type and extent of the inflammatory process since it has also been reported that COX is inhibited by NO (30).

Besides its proinflammatory role, a feature of NO that is not shared by PG is its potent cytotoxic effect. This could explain why in arthritis a nonsteroidal antiinflammatory such as indomethacin, by blocking PG production but not NO, allievates the symptoms associated with the inflammatory insult but does not modify the course of the disease (for review see reference 31). The production of low amounts of NO and PG from the constitutive enzymes appears to regulate a number of important physiological processes including the inhibition of platelet aggregation and white blood cell adhesion, regulation of blood 
vessel tone, and cytoprotection in the kidney and intestinal mucosa. It is therefore imperative to preserve cNOS and COX-1 activity in an inflammatory setting. This can be achieved by the use of glucocorticoids. The potent antiinflammatory glucocorticoid dexamethasone is a perfect example of a dual iNOS (for reviews see references 1 and 2) and COX-2 (for reviews see references 4 and 5) synthesis inhibitor. Unfortunately, serious side effects of steroids, independent of their ability to block iNOS and COX-2 expression, limit their clinical use. Agents such as L-NIL may have the advantage of not only alleviating inflammatory symptoms through dual inhibition of NO and NOdriven COX-2 activation, but also, by removing the cytotoxic effects of NO, may prove to be important disease modifying drugs. Furthermore, the combination of a selective iNOS inhibitor together with a COX-2 selective inhibitor may be beneficial in the treatment of inflammatory disorders, suppressing most of the proinflammatory actions of NO and PG without affecting the physiological properties of these very important mediators.

\section{Acknowledgments}

The authors would like to thank Thomas Misko for providing the iNOS antibodies, R. Keith Webber and F. Siong Tjoeng for synthesizing LNIL, Tracey Beasly for $\mathrm{PGE}_{2}$ analysis, and Linda Branson for blood pressure determinations.

\section{References}

1. Moncada, S., R. M. J. Palmer, and E. A. Higgs. 1991. Nitric oxide: physiology, pathophysiology and pharmacology. Pharmacol. Rev. 43:109-141.

2. Moncada, S., and A. Higgs. 1993. The L-Arginine-nitric oxide pathway. $N$. Engl. J. Med. 329:2002-2012.

3. DeWitt, D. L. 1991. Prostaglandin endoperoxide synthase: regulation of enzyme expression. Biochim. Biophys. Acta. 1083:121-134.

4. Masferrer, J. L., and K. Seibert. 1994. Regulation of prostaglandin synthesis by glucocorticoids. Receptor. 94:25-30.

5. Seibert, K., and J. Masferrer. 1994. Role of inducible cyclooxygenase (COX-2) in inflammation. Receptor. 94:17-23.

6. Fu, J. Y., J. L. Masferrer, K. Seibert, A. Raz, and P. Needleman. 1989. The induction and suppression of prostaglandin $\mathrm{H}_{2}$ synthase (cyclooxygenase) in human monocytes. J. Biol. Chem. 265:16737-16740.

7. Masferrer, J. L., B. S. Zweifel, K. Seibert, and P. Needleman. 1990. Selective regulation of cellular cyclooxygenase by dexamethasone and endotoxin in mice. J. Clin. Invest. 86:1375-1379.

8. Masferrer, J. L., K. Seibert, B. S. Zweifel, and P. Needleman. 1992. Endogenous glucocorticoids regulate an inducible cyclooxygenase enzyme. Proc. Natl. Acad. Sci. USA. 89:3917-3921.

9. Masferrer, J. L., S. T. Reddy, B. S. Zweifel, P. Needleman, R. S. Gilbert, and H. R. Herschman. 1994. In vivo regulation of cyclooxygenase-2 but not cyclooxygenase-1 by glucocorticoids in peritoneal macrophages. J. Pharmacol. Exp. Ther. 270:1340-1344.

10. Salvemini, D., T. P. Misko, J. L. Masferrer, K. Seibert, M. G. Currie, and P. Needleman. 1993. Nitric oxide activates cyclooxygenase enzymes. Proc. Natl. Acad. Sci. USA. 90:7240-7244.

11. Hajjar, D. P., H. M. Lander, S. A. F. Pearce, and K. B. Pomerantz. 1994. Evidence for nitric oxide induction of cyclooxygenase-1 activity by hemeindependent mechanisms. FASEB (Fed. Am. Soc. Exp. Biol.) J. 10:A1432.

12. Salvemini, D., K. Seibert, J. L. Masferrer, T. P. Misko, M. G. Currie, and
P. Needleman. 1994. Endogenous nitric oxide enhances prostaglandin production in a model of renal inflammation. J. Clin. Invest. 93:1940-1947.

13. Rettori, V., M. Gimeno, K. Lyson, and S. M. McCann. 1992. Nitric oxide mediates norepinephrine-induced prostaglandin $\mathrm{E}_{2}$ release from the hypothalamus. Proc. Natl. Acad. Sci. USA. 89:11543-11546.

14. Inoue, T., K. Fukuo, S. Morimoto, E. Koh, and T. Ogihara. 1993. Nitric oxide mediates interleukin-1-induced prostaglandin $E_{2}$ production by vascular smooth muscle cells. Biochem. Biophys. Res. Commun. 194:420-424.

15. Corbett, J. A., G. Kwon, J. Turk, and M. L. McDaniel. 1993. IL1 $\beta$ induces the coexpression of both nitric oxide synthase and cyclooxygenase by islets of Langerhans: activation of cyclooxygenase by nitric oxide. Biochemistry. 32:13767-13770

16. Sedgwick, A. D., Y. M. Sin, J. C. W. Edwards, and D. A. Willoughby. 1983. Increased inflammatory reactivity in newly formed lining tissue. J. Pathol. 141:483-495

17. Sedwick, A. D., and P. Lees. 1986. Studies of eicosanoid production in the air pouch model of synovial inflammation. Agents Actions. 18:429-438.

18. Misko, T. P., R. J. Schilling, D. Salvemini, W. M. Moore, and M. G. Currie. 1993. A fluorometric assay for the measurement of nitrite in biological samples. Anal. Biochem. 214:11-16.

19. Souhami, R. L., J. W. B. Bradfield, and N. E. Parker. 1977. The effect of cytotoxic drugs on the formation of mononuclear phagocytes. In Perspectives in Inflammation. D. A. Willoughby, J. P. Giroud, and G. P. Velo, editors. MTP Press, New York. 29-39.

20. Connor, J. A., P. T. Manning, S. L. Settle, W. M. Moore, G. M. Jerome, R. K. Webber, F. S. Tjoeng, and M. G. Currie. 1995. Suppression of adjuvantinduced arthritis by selective inhibition of inducible nitric oxide synthase. Eur. J. Pharmacol. 273:15-24.

21. Masferrer, J. L., B. S. Zweifel, P. T. Manning, S. D. Hauser, K. Leahy, Q. W. G. Smoth, P. C. Isakson, and K. Seibert. 1994. Selective inhibition of inducible cyclooxygenase 2 in vivo is antiinflammatory and nonulcerogenic. Proc. Natl. Acad. Sci. USA. 91:3228-3232.

22. Radomski, M. W., R. M. J. Palmer, and S. Moncada. 1990. Glucocorticoids inhibit the expression of an inducible but not the constitutive nitric oxide synthase in vascular endothelial cells. Proc. Natl. Acad. Sci. USA. 87:10043-10047.

23. Knowles, R. G., M. Salter, S. L. Brooks, and S. Moncada. 1990. Antiinflammatory glucocorticoids inhibit the induction by endotoxin of nitric oxide synthase in the lung, liver and aorta of the rat. Biochem. Biophys. Res. Commun. 172:1042-1048.

24. Rees, D. D., S. Cellek, R. M. J. Palmer, and S. Moncada. 1990. Dexamethasone prevents the induction by endotoxin of a nitric oxide synthase and the associated effects on vascular tone: an insight into endotoxin shock. Biochem. Biophys. Res. Commun. 173:541-547.

25. Moore, W. M., R. K. Webber, G. M. Jerome, F. S. Tjoeng, T. P. Misko, and M. G. Currie. 1994. L- $N^{6}$-(1-Iminoethyl)lysine: a selective inhibitor of inducible nitric oxide synthase. J. Med. Chem. 37:3886-3888.

26. Futaki, N., K. Yoshikawa, Y. Hamasaka, I Arai, S. Higuchi, H. Iizuka, and S. Otomo. 1993. NS-398, a novel non-steroidal antiinflammatory drug with potent analgesic and antipyretic effects, which causes minimal stomach lesions. Gen. Pharmacol. 24:105-110.

27. Futaki, N., I. Arai, Y. Hamasaka, S. Takahashi, S. Higuchi, and S. Otomo. 1993. Selective inhibition of NS398 on prostanoid production in inflamed tissue in carrageenan-air-pouch inflammation. J. Pharm. Pharmacol. 45:753-755.

28. Salvemini, D., S. L. Settle, J. L. Masferrer, K. Seibert, M. G. Currie, and P. Needleman. 1995. Regulation of prostaglandin production by nitric oxide: an in vivo analysis. Br. J. Pharmacol. 114:1171-1178.

29. Moore, P. K., O. A. Al Slayeh, N. W. S. Chong, R. A. Evans, and A. Gibson. 1990. L- $N^{\mathrm{G}}$-nitro arginine (L-NOARG), a novel, $\mathrm{L}$-arginine reversible inhibitor of endothelium dependent vasodilation in vitro. Br. J. Pharmacol. 99:408-412.

30. Vane, J. R., J. A. Mitchell, I. Appleton, A. Tomlinson, D. Bishop-Bailey, J. Croxtall, and D. A. Willoughby. 1994. Inducible isoforms of cyclooxygenase and nitric-oxide synthase in inflammation. Proc. Natl. Acad. Sci. USA 91:20462050.

31. Flynn, B. L. 1994. Rheumatoid arthritis and osteoarthritis: current and future therapies. Am. Pharm. 34:31-42. 